\title{
Reduction of galectin-3 expression and liver fibrosis after cell therapy in a mouse model of cirrhosis
}

\author{
SHEILLA ANDRADE DE OLIVEIRA ${ }^{1,2 *}$, BRUNO SOLANO DE FREITAS SOUZA ${ }^{2,3 *}$, \\ ELTON PEREIRA SÁ BARRETO ${ }^{2}$, CARLA MARTINS KANETO ${ }^{3}$, \\ HÉLIO ALMEIDA NETO ${ }^{2,3}$, CARINE MACHADO AZEVEDO ${ }^{2,3}$, \\ ELISALVA TEIXEIRA GUIMARÃES ${ }^{2}$, LUIZ ANTONIO RODRIGUES DE FREITAS ${ }^{3,4}$, \\ RICARDO RIBEIRO-DOS-SANTOS ${ }^{2,3}$ \& MILENA BOTELHO PEREIRA SOARES ${ }^{2,3}$
}

\author{
${ }^{1}$ Centro de Pesquisas Aggeu Magalhães, Fundação Oswaldo Cruz, Recife, Pernambuco, Brazil, ${ }^{2}$ Centro de Pesquisas \\ Gonçalo Moniz, Fundação Oswaldo Cruz, Salvador, Bahia, Brazil, ${ }^{3}$ Hospital São Rafael, Salvador, Bahia, Brazil, \\ and ${ }^{4}$ Universidade Federal da Bahia, Salvador, Bahia, Brazil
}

\begin{abstract}
Background aims. Cirrhosis, end-stage liver disease, is caused by different mechanisms of injury, associated with persistent inflammation. Galectin-3 is an important regulator of fibrosis that links chronic inflammation to fibrogenesis. We investigated the role of bone marrow cell (BMC) transplantation in chronic inflammation and hepatic fibrosis. Methods. Liver cirrhosis was induced by administration of carbon tetrachloride and ethanol to wild-type C57BL/6 or bone marrow chimeric mice. Bone marrow chimeras were generated by lethal irradiation and transplantation with BMC obtained from green fluorescent protein $\left(\mathrm{GFP}^{+}\right)$donors. Wild-type cirrhotic mice were transplanted with BMC without irradiation. Livers from chimeras and cirrhotic transplanted mice were obtained for evaluation of inflammation, fibrosis and regulatory factors [galectin-3, matrix metallopeptidase (MMP)-9, tissue inhibitor of metalloproteinase (TIMP)-1 and transforming growth factor (TGF)- $\beta$ ]. Results. The development of cirrhosis was associated with increased expression of galectin- 3 by $\mathrm{F} / 80^{+}$cells and intense migration of BMC to the liver. Furthermore, when transplanted after the establishment of cirrhosis, BMC also migrated to the liver and localized within the fibrous septa. Two months after BMC therapy, cirrhotic mice had a significant reduction in liver fibrosis and expression of type I collagen. We did not find any difference in levels of TGF- $\beta$, TIMP-1 and MMP-9 between saline and BMC groups. However, the numbers of inflammatory cells, phagocytes and galectin- $3^{+}$cells were markedly lower in the livers of cirrhotic mice treated with BMC. Conclusions. Our results demonstrate an important role for BMC in the regulation of liver fibrosis and that transplantation of BMC can accelerate fibrosis regression through modulatory mechanisms.
\end{abstract}

Key Words: carbon tetrachloride, galectin-3, hepatic cirrhosis, mice, stem cells

\section{Introduction}

Cirrhosis is the end stage of many chronic liver diseases and represents a therapeutic challenge world-wide (1-3). The development of cirrhosis is initiated after repeated insults that cause chronic liver tissue damage, consequently inducing fibrosis and nodular regeneration of liver cells. This process is frequently associated with an inflammatory response and the activation of hepatic stellate cells, known as the most important source of extracellular matrix (ECM) production, along with different subtypes of myofibroblasts, such as fibrogenic cells from the epithelial-to-mesenchymal transition, periportal fibrocytes, and bone marrowderived fibrocytes that synthesize ECM proteins $(4,5)$. Persistent noxious stimuli lead to chronic activation of macrophages and synthesis of molecules that promote fibrogenesis, such as galectin-3, a lectin that regulates a wide variety of biologic phenomena, establishing a link between chronic inflammation and fibrogenesis (6).

It has been shown that galectin-3 activates and stimulates the proliferation of myofibroblasts as well as increases their synthesis of collagen (7). Furthermore, galectin-3 expression has been associated with the development of fibrosis in a variety of organs, such as the kidney, liver, gut and heart $(8,9)$. As a result of the persistent stimulus to fibrogenesis, with increased galectin- 3 expression, profound alterations in the liver architecture occur, modifying the relationship between stromal components, vessels and hepatocytes, ultimately characterizing liver cirrhosis (10).

*These authors contributed equally to this work.

Correspondence: Milena B. P. Soares, Centro de Pesquisas Gonçalo Moniz, Fundação Oswaldo Cruz, Rua Waldemar Falcão, 121, Candeal, Salvador, BA, CEP 40296-710. E-mail: milena@bahia.fiocruz.br 
Liver transplantation is the only effective treatment available for patients with cirrhosis presenting chronic hepatic failure $(2,11)$, and it remains a high-risk procedure limited by the availability of donated organs. In this context, the development of new therapeutic strategies for liver failure is necessary. Stem cell therapy has emerged as a potential tool in the treatment of liver disease (12). In recent years, many experimental studies have been carried out to evaluate the therapeutic efficacy of stem cells in models of acute hepatic injuries (13-24). Although the results have been promising, further studies on models of chronic liver disease are necessary. There is also a need to understand the mechanisms by which stem cell therapy can be beneficial in treating liver disease (25).

Cell therapy can act through a variety of mechanisms, either directly or indirectly by secretion of molecules that can counteract fibrogenesis, such as soluble mediators and metalloproteinases $(21,26)$. The present study evaluated the effects of bone marrow cells (BMC) transplanted in mice with cirrhosis induced by long-term administration of carbon tetrachloride and ethanol $\left(\mathrm{CCl}_{4}+\mathrm{EtOH}\right)$. Our results demonstrate the therapeutic potential of BMC in a well-established cirrhosis model and reinforce the idea that galectin-3 may be a potential intervention target in the treatment of liver fibrosis.

\section{Methods}

\section{Ethics statement}

Prior to undertaking the studies described here, approval for all the experiments using mice was obtained from the Gonçalo Moniz Research Center (CPqGM), Fundação Oswaldo Cruz (FIOCRUZ; Salvador, Bahia, Brazil) Ethics Committee and certified as 001/2007, protocol number 24 .

\section{Animals}

Three-week-old male C57BL/6 wild-type and female enhanced green fluorescent protein (eGFP)transgenic mice were used as recipients and donors of BMC, respectively. All the animals, weighing between 20 and 23 g, were raised and maintained at the Gonçalo Moniz Research Center/ FIOCRUZ, in rooms with a controlled temperature $\left(22 \pm 2^{\circ} \mathrm{C}\right)$ and humidity $(55 \pm 10 \%)$ environment under continuous air renovation conditions. Animals were housed in a 12-h light/12-h dark cycle (6.00-18.00) with rodent diet and water ad libitum.

\section{Generation of bone marrow chimeras}

C57BL/ 6 female mice were irradiated with 6 Gy for depletion of BMC (Figure 1A) in a ${ }^{137}$ Cesium source irradiator (CisBio International, Gif Sur Yvette France). BMC were obtained from the femurs and tibiae of male eGFP transgenic mice and used to reconstitute irradiated mice. The mononuclear cells were purified by centrifugation in Ficoll gradient at $1000 \mathrm{~g}$ for $15 \mathrm{~min}$ (Histopaque 1119 and $1077 ; 1: 1$; Sigma, St Louis, MO, USA). After two washings in Dulbecco's modified Eagle medium (DMEM) medium (Sigma), the cells were filtered and resuspended in saline. Each irradiated mouse received an injection of $10^{7}$ cells. Two weeks later, representative animals were killed and $\mathrm{BMC}$ were harvested to confirm repopulation by donor cells using flow cytometry analysis.

\section{Induction of hepatic injury and cirrhosis}

Experimental cirrhosis was induced in wild-type and chimeric mice by administration of $0.2 \mathrm{~mL} 20 \% \mathrm{CCl}_{4}$ dissolved in a mineral oil solution (Merck, Darmstadt, Germany) and diluted in olive oil through gavage twice a week, combined with 5\% (v/v) ethanol $(\mathrm{EtOH})$ in the drinking water (Figure 1B). Control mice were maintained in the same housing conditions as the experimental groups. Groups of animals were killed for evaluation after periods of 24 days, 2-3 months and 5-6 months.

\section{Morphologic and morphometric hepatic analyzes}

Mice under anesthesia were perfused through the heart with $50 \mathrm{~mL}$ phosphate-buffered saline (PBS) followed by $200 \mathrm{~mL}$ paraformaldehyde at $4^{\circ} \mathrm{C}$. Liver slices were fixed in $10 \%$ formalin and embedded in paraffin. Five micrometer-thick sections were stained with either hematoxylin-eosin $(\mathrm{H} \& \mathrm{E})$ for histologic analysis and to quantify inflammation, or picrosirius red to quantify fibrosis. Analyzes were performed on whole liver sections after slide scanning using the Aperio ScanScope system (Aperio Technologies, Vista, CA, USA). The images were analyzed used the Image Pro program (version 7.0; Media Cybernetics, San Diego, CA, USA). A mean area of 54 $636978 \mu \mathrm{m}^{2} /$ mouse was analyzed.

Cirrhosis was defined by the presence of hepatic cell nodules delimited by fibrosis occupying most of the liver parenchyma. The morphologic parameters analyzed were presence of steatosis, ballooning cells, apoptosis, necrosis, Mallory-Denk bodies, ductular proliferation and inflammation (portal and acinar). These parameters were classified according to intensity in five grades, ranging from 0 to 4 .

\section{Transplantation of BMC to wild-type C57BL/6 mice}

Six months after treatment with $\mathrm{CCl}_{4}+\mathrm{EtOH}$, the administration of these drugs was suspended and the 

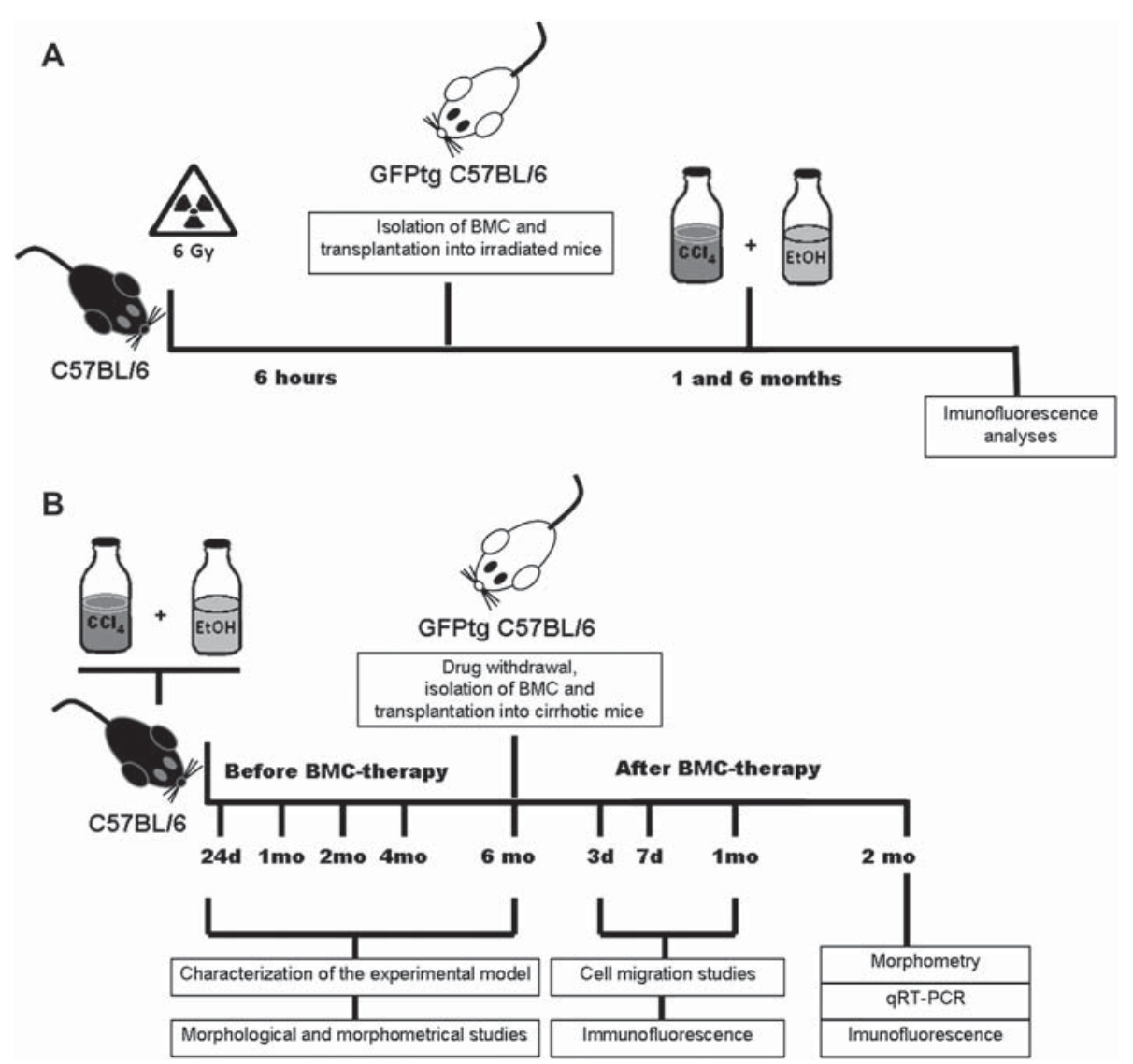

Figure 1. A schematic illustration of the experimental design. Generation of bone marrow chimeras and hepatic injury (A). C57BL/6 female mice were irradiated $(6 \mathrm{~Gy})$ and transplanted with $\mathrm{BMC}$ obtained from $\mathrm{GFP}^{+}$donors $\left(10^{7} \mathrm{cells} / \mathrm{mouse}\right)$. Chimeric mice were submitted to a cirrhosis-induction protocol with administration of $\mathrm{CCl}_{4}+\mathrm{EtOH}$, and were killed 1 month $(n=5)$ or 6 months $(n=5)$ later. Control chimeric mice remained without injury at the same time-points $(n=10)$. Induction of experimental liver cirrhosis and therapy with BMC (B). Groups of mice were treated with $\mathrm{CCl}_{4}+\mathrm{EtOH}$. Normal controls were maintained in the same housing conditions. Mice were killed for morphologic evaluations and characterization of the experimental model $(n=4 /$ time-point $)$ after different periods of $\mathrm{CCl}_{4}+\mathrm{EtOH}$ administration (24 days and 2, 3, 5 and 6 months). Cirrhotic mice (treated for 6 months with $\mathrm{CCl}_{4}+\mathrm{EtOH}$ ) were transplanted with BMC or injected with saline and killed 2 months later for morphometric, immunofluorescence and qRT-PCR studies $(n=5-8$ mice/group).

wild-type C57BL/6 mice were submitted to BMC transplantation (Figure 1B). BMC were obtained from femurs and tibiae of C57BL/6 eGFP transgenic mice. $\mathrm{BMC}$ were purified by centrifugation in a Ficoll gradient (Histopaque 1119 and 1077, 1:1; Sigma-Aldrich, St Louis, MO, USA) at $1000 \mathrm{~g}$ for $15 \mathrm{~min}$. BMC were suspended in saline and injected into the cirrhotic wild-type $\mathrm{C} 57 \mathrm{BL} / 6$ mice. The isolated BMC were analyzed using flow cytometry with the following conjugated antibodies from Becton Dickinson (San Diego, CA, USA): stem cell antigen-1(Sca-1)-phycoerythrin (PE)/Cyanine (Cy) 5, CD45-Allophycocyanin(APC), CD44-PE, CD34-PE, CD11b-PE and CD117-PE. Acquisition and analysis were performed in a FACScalibur flow cytometer (Becton Dickinson). The following percentages were obtained: $96.51 \pm 1.32$ for $\mathrm{GFP}^{+}$ cells, $0.11 \pm 0.032$ for $\mathrm{Sca}^{-1}{ }^{+}$cells, $96.35 \pm 3.12$ for $\mathrm{CD}_{4} 5^{+}$cells, $92.72 \pm 3.23$ for $\mathrm{CD} 44^{+}$cells, $0.02 \pm 0.05$ for $\mathrm{CD}^{2} 4^{+}$cells, $60.22 \pm 5.71$ for $\mathrm{CD}_{11} \mathrm{~b}^{+}$cells and $0.17 \pm 0.04$ for $\mathrm{CD} 117^{+}$cells.
One or three doses of $3 \times 10^{7}$ cells/mouse were administered intravenously, via the retro-orbital plexus, with 7 days between injections. Control cirrhotic mice received saline injections at similar intervals. Mice were killed at various time-points after cell treatment.

\section{Immunofluorescence analysis}

The $5-\mu \mathrm{m}$ frozen sections obtained from the livers of mice were fixed in $4 \%$ cold paraformaldehyde in a $0.1 \mathrm{M}$ phosphate buffer. The presence of transplanted $\mathrm{GFP}^{+} \mathrm{BMC}$ in the liver tissue was analyzed using direct fluorescence microscopy. The following antibodies were used: anti-cytokeratin-18, diluted 1:100 (Santa Cruz Biotechnology, Santa Cruz, California, USA); anti-CD45, diluted 1:100 (Caltag, Buckingham, UK); anti-albumin, diluted 1:400 (DAKO, Glostrup, Denmark); and antigalectin-3, diluted 1:50 (Santa Cruz Biotechnology). Nuclei were counterstained with 4,6-dismidino2-phenylindole (VectaShield hard set mounting 
medium with DAPI H-1500; Vector Laboratories, Burlingame, CA, USA). The presence of fluorescent cells was observed using an AX70 microscope with an epifluorescence system plus grid to enhance the fluorescence resolution (Optigrid, structured light imaging system; Thales Optem Inc., Olympus, Center Valley, PA, USA), using appropriate filters (Olympus) in a FluoView 1000 confocal microscope (Olympus, Optigrid, Fairport, NY, USA). Quantification of galectin- $3^{+}$cells, autofluorescent cells and type I collagen were performed in 10 random fields per section. Cell images were captured using $400 \times$ magnification and analyzed using Image Pro Plus software.

\section{Real-time-polymerase chain reaction}

Total RNA was isolated from the livers using TRIzol reagent (Invitrogen, Carlsbad, CA, USA), and the concentration was determined by photometric measurement. A high-capacity cDNA reverse transcription kit (Applied Biosystems, Foster City, CA, USA) was used to synthesize cDNA from 1 $\mu \mathrm{g}$ RNA, in accordance with manufacturer's recommendations. Real-time-polymerase chain reaction (qRT-PCR) assays were performed to detect the expression levels of transforming growth factor (TGF)- $\beta 1$, tissue inhibitor of metalloproteinase (TIMP)-1 and matrix metallopeptidase (MMP)-9 genes. qRT-PCR amplification mixtures contained 20 ๆg template cDNA, and Taqman master mix $(10 \mu \mathrm{L})$ (Applied Biosystems) probes for TGF- $\beta$ (Mm00441724_m1), TIMP-1 (Mm00441818_m1) and MMP-9 (Mm00442991_m1) in a final volume of $20 \mu \mathrm{L}$. All reactions were run in duplicate on an ABI7500 sequence detection system (Applied Biosystems) under standard thermal cycling conditions. The mean cycle threshold $(C t)$ values from duplicate measurements were used to calculate expression of the target gene, with normalization to an internal control glyceraldehyde-3-phosphate dehydrogenase (GAPDH) using the $2-\mathrm{DC} t$ formula. Experiments with coefficients of variation greater than $5 \%$ were excluded. A no-template control (NTC) and noreverse transcription controls (No-RT) were also included.

\section{Statistical analysis}

Data were analyzed using a Student's $t$-test or ANOva, followed by Newman-Keuls (TGF- $\beta$ and morphometry) or Tukey (qRT-PCR) tests, using Prism Software (version 5.0; GraphPad Software, San Diego, CA, USA). Differences were considered significant if $P$ was equal to or less than 0.05 .

\section{Results}

Cirrhosis induction in mice chronically treated with $\mathrm{CCl}_{4}+\mathrm{EtOH}$

Chronic administration of $\mathrm{CCl}_{4}+\mathrm{EtOH}$ caused progressive morphologic alterations in the liver. After 6 months of repeated administration of $\mathrm{CCl}_{4}+\mathrm{EtOH}$, the livers exhibited morphologic alterations, such as a nodular surface and brownish coloring (Figure 2A, B). The normal parenchyma was replaced by regenerative nodules (Figure 2C, D) measuring $453 \pm 199 \mu \mathrm{m}$ in diameter (ranging from 196 to $770 \mu \mathrm{m}$ ) delimited by fibrous septa. Vascular alterations, including portal vein dilation, were observed (Figure 2A). The survival
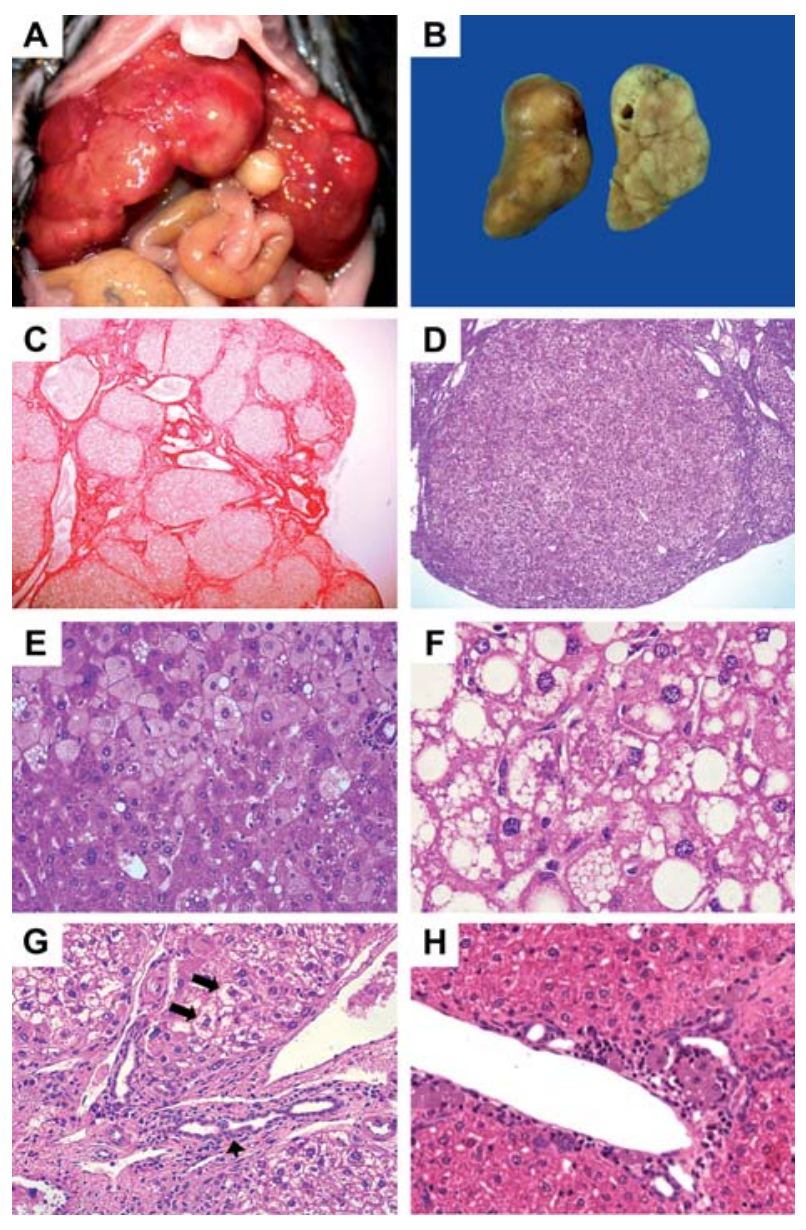

Figure 2. Macroscopic and morphologic aspects of cirrhosis in mice submitted to $\mathrm{CCl}_{4}+\mathrm{EtOH}$ administration for 6 months. Prominent areas of nodules on the liver surface of cirrhotic mice (A,B). Hepatic nodules of variable size subdivided into irregular fibrous septa could be seen in the picrosirius red-stained section by optical microscopy (c) $(40 \times)$. Regenerative macronodule (D) $(H \& E, 100 \times)$. Ballooning cells $(\mathrm{E})(\mathrm{H} \& \mathrm{E}, 200 \times)$ and the presence of micro- and macrovacuolar steatosis $(\mathrm{F})(\mathrm{H} \& \mathrm{E}, 400 \times)$. Proliferation of ductular cells $(\mathrm{G})$ and the presence of Mallory bodies (G, arrows) (H\&E, 200 $\times$ ). After 6 months of $\mathrm{CCl}_{4}+\mathrm{EtOH}$ treatment, the foci of periportal chronic inflammation associated with large phagocytic cells ( $D$, arrows) were seen with $\mathrm{H} \& \mathrm{E}$ staining $(\mathrm{H})(200 \times)$. 
during 6 months of $\mathrm{CCl}_{4}+\mathrm{EtOH}$ administration was about $70 \%$ (37/53).

Short-termadministration (24 days) of $\mathrm{CCl}_{4}+\mathrm{EtOH}$ induced hepatic cell necrosis and a mixed inflammatory infiltrate with a predominance of mononuclear cells, especially in centrilobular areas (data not shown). At this time-point, mild hepatocellular ballooning without steatosis was observed. Some incomplete fibrous septa linking vascular structures were also observed. After a longer period of $\mathrm{CCl}_{4}+\mathrm{EtOH}$ administration (2-5 months), the normal liver architecture was partially replaced by nodules of regenerating liver cells surrounded by fibrous septa. At this time-point, a mild ductular proliferation was present within portal tracts, as well as in fibrous septa (data not shown).

Cirrhosis was established after 6 months of continuous $\mathrm{CCl}_{4}+\mathrm{EtOH}$ administration, and characterized by a diffuse liver alteration with fibrous tissue completely surrounding nodules of regenerative hepatocytes, resulting in profound alteration of the liver architecture (Figure 2C, D). Some cirrhotic nodules showed microvacuolar hepatocellular steatosis and foci ballooning cells (Figure 2E, F), and hyaline Mallory-Denk bodies were frequently observed
(Figure 2G). Ductular cell proliferation was observed in connective tissue (Figure 2G).

Foci of inflammatory cells were seen within the fibrous septa (Figure 2H) Immunostaining for $\mathrm{F} 4 / 80^{+}$, a macrophage cell marker, demonstrated that many of the inflammatory cells were macrophages (Figure 3A). Among these cells, some showed an abundant clear brown cytoplasm. These cells had autofluorescent granules, were positive for the $\mathrm{F} 4 / 80^{+}$marker and also for galectin-3 (Figure $3 \mathrm{~B}, \mathrm{C})$. These cells were observed in greater quantities at later time-points (Figure 3D-F), although some $\mathrm{F} 4 / 80^{+}$cells remained negative for galectin-3 (Figure 3C, detail).

\section{Migration of BMC to injured liver}

In order to evaluate the recruitment of BMC during the development of cirrhosis, bone marrow chimeras were generated and submitted to treatment with $\mathrm{CCl}_{4}+\mathrm{EtOH}$ or remained as uninjured controls. Acute and chronic hepatic injury induced by $\mathrm{CCl}_{4}+\mathrm{EtOH}$ resulted in an increase in the recruitment of BMC to the liver, compared with control animals. $\mathrm{GFP}^{+}$cell numbers were found to be 2 -fold increased in acutely
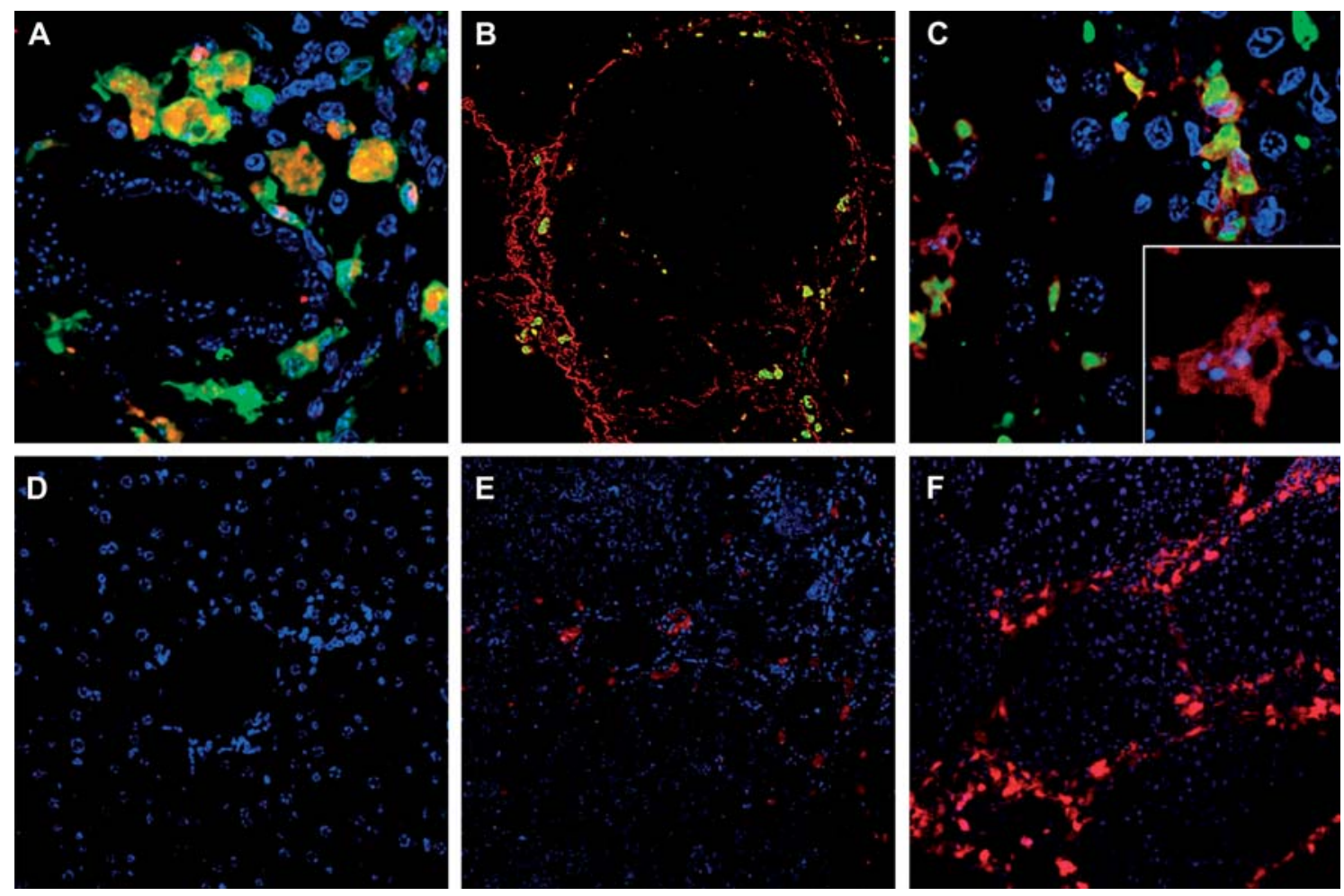

Figure 3. Presence of galectin- $3^{+}$cells during the establishment of experimental cirrhosis. Phagocytic cells found in inflammatory infiltrates had deposits of autofluorescent material (red) and were also positive for F4/80 (green) (A) $(1200 \times$ ). Picrosirius staining visualized by fluorescence microscopy showed the presence of autofluorescent cells (yellow) associated with fibrous septa (red) (B) (100 $\times$ ). Most galectin- $3^{+}$(red) cells co-stained with F4/80 (green; C) $\left(1200 \times\right.$ ) and a few galectin- $3^{+}$cells were F4-80- (C, detail). Immunofluorescence staining with anti-galectin-3 (red) and DAPI (blue) in liver sections of non-injured mice (D) $(400 \times)$ and $\mathrm{CCl}_{4}+\mathrm{EtOH}^{-t r e a t e d ~ m i c e ~ f o r ~}$ 2 months $(E)(200 \times)$ and 6 months $(F)(200 \times)$, which showed increased numbers of galectin- $3^{+}$cells with time and their typical localization in areas of fibrous septa (F) $(200 \times)$. 

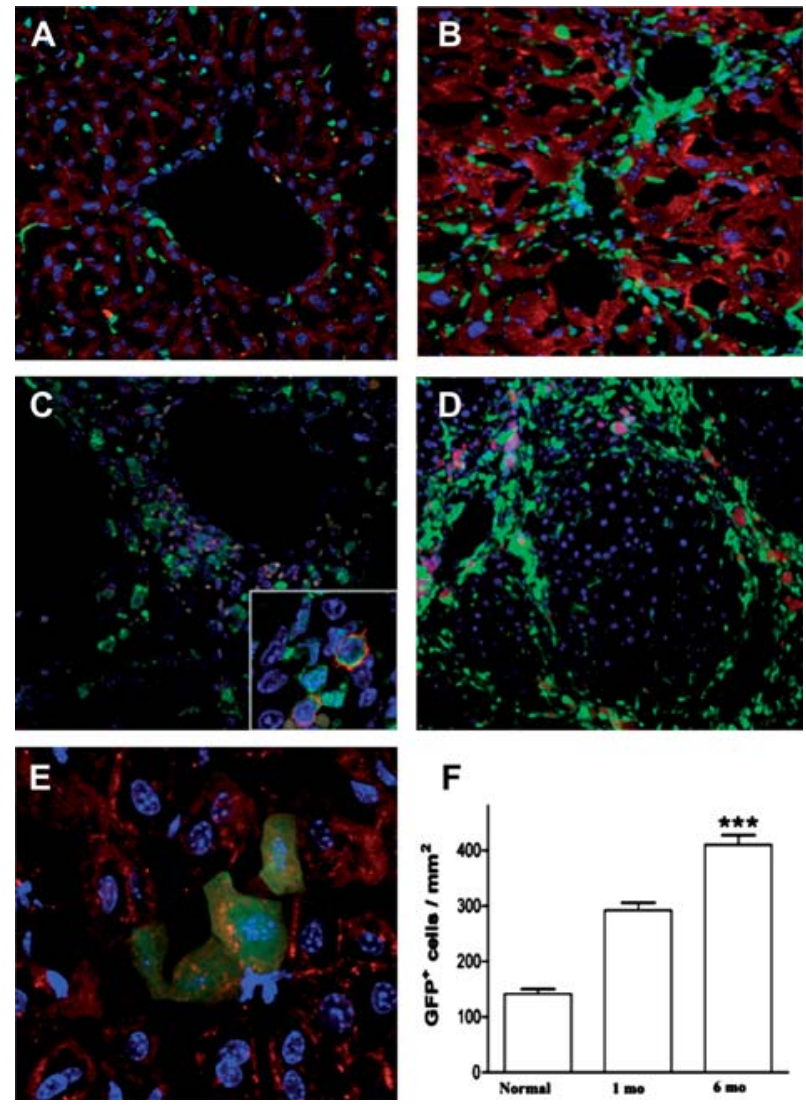

Figure 4. BMC migrate to the injured liver in chimeric mice Immunofluorescence for detection of GFP (green), albumin (red) and nuclear counterstaining with DAPI (blue). Bone marrow $\mathrm{GFP}^{+}$positive cells were found in small numbers in sinusoids of non-injured chimeras (A) $(400 \times)$ and at greater numbers in perivascular regions of acutely injured chimeras after 30 days of $\mathrm{CCl}_{4}{ }^{+}$EtOH treatment $(\mathrm{B})(400 \times)$. Most infiltrating $\mathrm{GFP}^{+}$cells (green) were found in periportal inflammatory infiltrates at 30 days of $\mathrm{CCl}_{4}+\mathrm{EtOH}$ treatment and co-stained with $\mathrm{CD} 45$ (red) $\left(\mathrm{C}\right.$, detail) $(200 \times)$. At 6 months of $\mathrm{CCl}_{4}+$ EtOH treatment, $\mathrm{GFP}^{+}$ cells (green) were mostly found in fibrous septa and some presented autofluorescent cytoplasmic deposits (red) (D) $(200 \times)$. Rarely, hepatocytes co-stained with albumin (red) and GFP (green) were visualized after 6 months of $\mathrm{CCl}_{4}+\mathrm{EtOH}$ treatment $(\mathrm{E})(800 \times)$. The $\mathrm{GFP}^{+}$cells were quantified in non-injured, 30-day injured and 6-months injured chimeras $(F)$. Data are represented as the means \pm SEM of five animals per group. $* P<0.05(\mathrm{~F})$.

injured livers compared with uninjured controls (Figure 4B, F), and the number was three times greater in chronically injured mice (Figure $4 \mathrm{C}-\mathrm{F}$ ). In the non-injured control group, $\mathrm{GFP}^{+}$cells were found predominantly in sinusoids (Figure 4A).

However, in acutely injured livers $\mathrm{GFP}^{+}$cells were seen around the central vein in the hepatic lobules (Figure 4C), whereas in chronically injured livers they were found mainly within the fibrous septa (Figure 4D). Few cells co-expressing GFP and albumin could be found in the hepatic parenchyma in chronically injured mice (Figure 4E), with none found in uninjured controls. The number of $\mathrm{GFP}^{+}$cells in the parenchyma of chimeric mice significantly increased at later time-points (Figure 4F).

In order to investigate whether BMC migrate to the livers of non-irradiated mice with established cirrhosis, the animals were transplanted intravenously with $3 \times 10^{7}$ bone marrow mononuclear cells obtained from GFP transgenic mice. $\mathrm{GFP}^{+} \mathrm{BMC}$ were found in the liver sections of cirrhotic mice 3 days after transplantation (Figure 5A). At this time-point, $\mathrm{GFP}^{+}$cells were mostly small and round in shape and were found in portal area tracts. One week after transplantation, $\mathrm{GFP}^{+}$ cells, mostly with an elongated shape, were found within the fibrous septa (Figure $5 \mathrm{~B}$ ). $\mathrm{GFP}^{+}$cells were not seen in the liver sections of mice analyzed 1 and 2 months after transplantation (data not shown).

\section{Effects of BMC transplantation in livers of cirrhotic mice}

To evaluate the effects of the transplanted cells into non-irradiated cirrhotic mice, liver sections were analyzed 2 months after the therapy with BMC. Mice were submitted to a 3-week protocol, with 1 -weekly intravenous injections of $3 \times 10^{7}$ cells. A reduction in fibrosis was observed in the BMCtreated mice, compared with controls (Figure 5C, D), which was confirmed by morphometric evaluation (Figure 6A). A marked reduction in collagen I was observed in the fibrous septa of livers from BMCtreated mice, compared with controls (Figure 6B). In addition, the number of inflammatory and large autofluorescent cells significantly decreased after BMC therapy (Figure 6C, D). In contrast with these results, transplantation of $\mathrm{BMC}$ to mice that were still receiving $\mathrm{CCl}_{4}+\mathrm{EtOH}$ between 4 and 6 months of the protocol did not lead to lower levels of fibrosis, compared with mice injected with saline (data not shown).

To investigate the mechanisms by which BMC therapy resulted in a reduction of fibrosis, we tested whether BMC transplantation modulated the production of the fibrogenic cytokine TGF- $\beta$. Liver TGF- $\beta$ mRNA levels in cirrhotic mice were increased compared with normal controls. However, no differences were observed in the group treated with BMC compared with saline-treated cirrhotic mice, as investigated by qRT-PCR analysis (Figure $6 \mathrm{E})$. Two additional factors associated with fibrosis, TIMP-1 and MMP-9, were also evaluated at the gene expression level. The same pattern of expression as found at the TGF- $\beta$ mRNA level was also observed with TIMP-1, a pro-fibrogenic factor. The expression of MMP-9, an anti-fibrogenic factor, was 

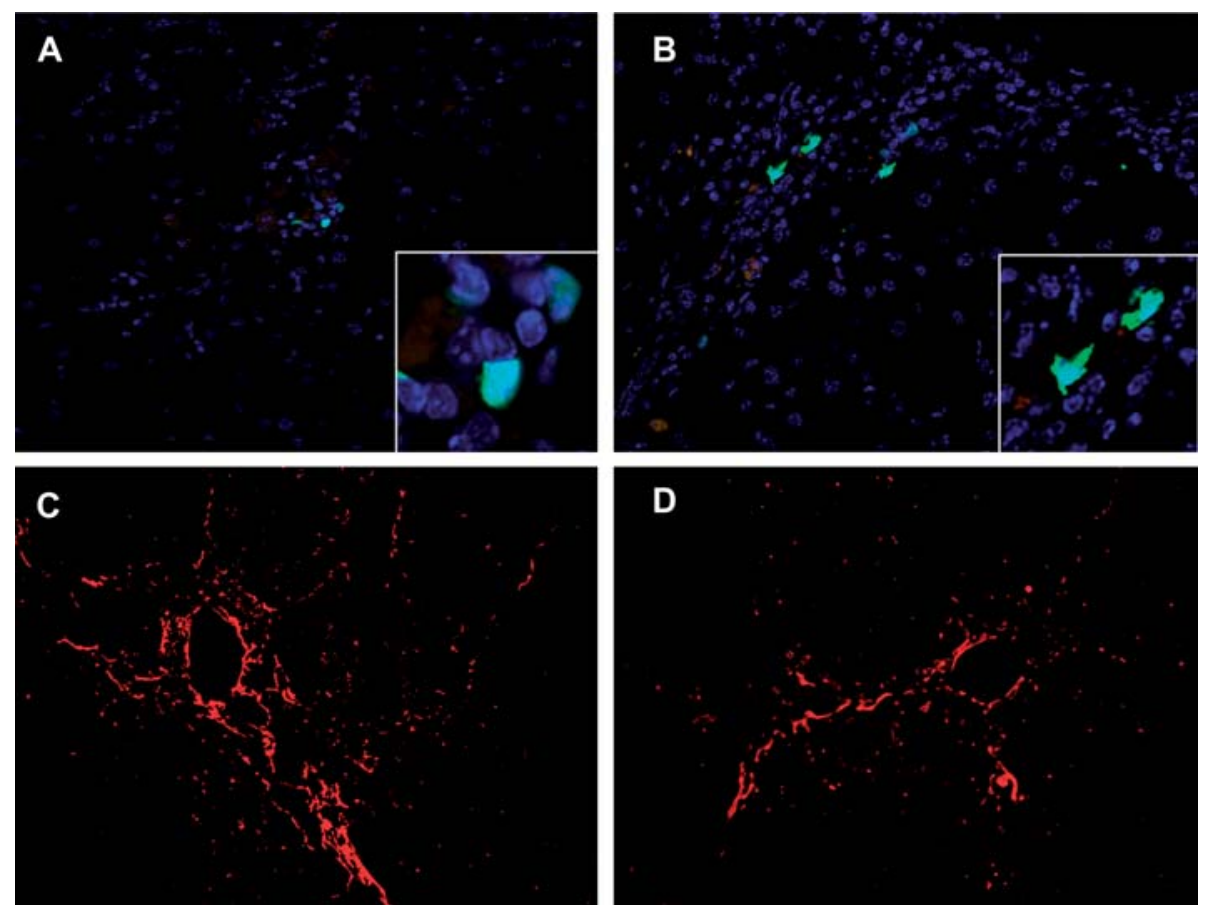

Figure 5. BMC migrate to cirrhotic liver and promote fibrosis reduction. Mice were transplanted intravenously with BMC after the establishment of cirrhosis and were killed 1 or 7 days later for fluorescence microscopy analysis. For visualization of GFP ${ }^{+}$cells (green), sections were mounted with nuclear counterstaining with DAPI (blue). Small, round-shaped GFP ${ }^{+}$cells were seen 1 day after the transplantation (A and detail), while $\mathrm{GFP}^{+}$with elongated shapes were seen in fibrous septa after 7 days (B and detail). Picrosirius red staining for detection of collagen in liver sections of saline-treated (C) and BMC-treated (D) mice.

found to be similar among all groups analyzed (data not shown).

\section{Reduction of galectin-3 expression after BMC treatment in livers of cirrhotic mice}

The expression of galectin-3 in the livers of cirrhotic mice was evaluated. Galectin-3+ cells were observed mainly in portal tracts and in fibrous septa in cirrhotic mice treated with saline (Figure 7A), whereas in the livers of BMC-treated cirrhotic mice galectin $-3^{+}$cells were observed only in portal tracts (Figure 7B). Morphometric analysis revealed a marked decrease in the number of galectin- $3^{+}$cells in the livers of mice 2 months after BMC transplantation, compared with saline-treated cirrhotic controls $(P<0.0001$; Figure 7C).

\section{Discussion}

A growing number of reports have shown that BMC transplantation mitigates liver damage in acute experimental models (13-16,18-20,22). In the present study we report the beneficial effects of BMC transplantation in an experimental model of cirrhosis, induced by chronic administration of $\mathrm{CCl}_{4}+\mathrm{EtOH}$. C57BL/6 mice chronically receiving $\mathrm{CCl}_{4}+\mathrm{EtOH}$ developed morphologic alterations that characterize liver cirrhosis, providing a useful tool for studying mechanisms of fibrogenesis and fibrosis regression, as well as for the development of novel potential therapies.

The bone marrow mononuclear cell fraction tested in our study comprises a number of cell types and therefore additional studies are needed to identify which cell populations are responsible for the beneficial effects observed. However, despite being a heterogeneous population, transplantation of BMC is already a well-established procedure in medical practice, which helps translation of the results to clinical studies. In this regard, initial clinical studies using autologous BMC transplantation in patients with chronic liver disease have been conducted by our group and others $(25,27)$.

Different populations of bone marrow-derived cells have been implicated in both the development as well as the regression of cirrhosis $(21,28)$. The establishment of chronic liver injury and its progression to cirrhosis involves the activation of hepatic stellate cells, which are converted into fibroblasts and myofibroblasts and become the main source of ECM in liver fibrosis. Furthermore, the potential role of other fibroblast subpopulations has been described, such as fibrogenic cells from the epithelial-to-mesenchymal transition, periportal fibrocytes and bone marrowderived cells (5). The role of BMC as another source 

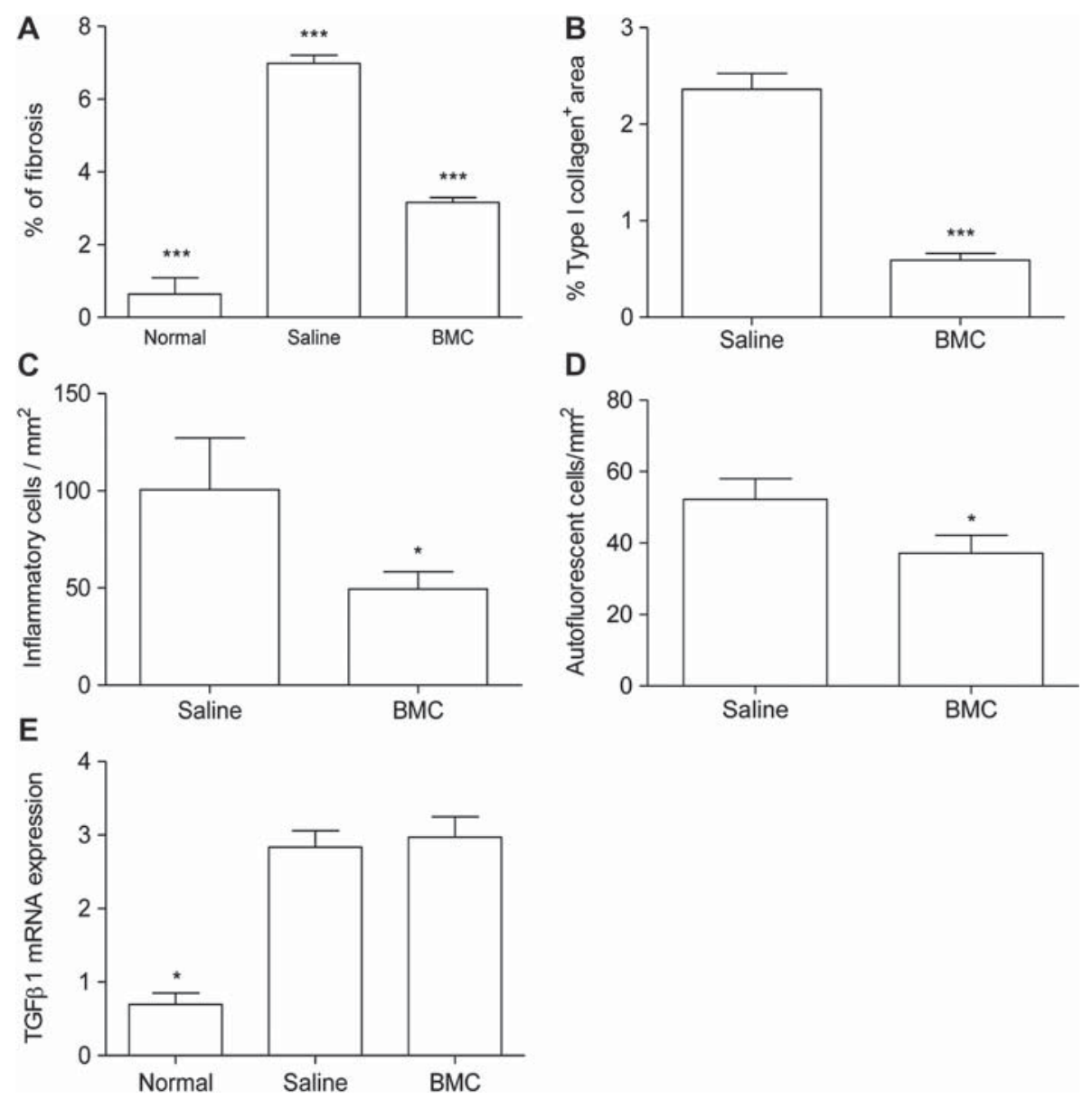

Figure 6. Effects observed after 2 months of BMC therapy on liver cirrhosis. Morphometric quantification of the percentage area of liver fibrosis assessed by picrosirius red staining (A) and immunostaining with anti-type I collagen (B), demonstrating fibrosis reduction in the BMC-treated group compared with the saline-treated group. Quantification of inflammatory cells (C) and autofluorescent cells (D) in liver sections showing reduced numbers in the BMC-treated group compared with the saline-treated group. TGF- $\beta$ levels assessed in liver homogenates by qRT-PCR (E). Data are represented graphically as the mean \pm SEM of five to eight mice/group. $* P<0.05$, $* * * P<0.0001$.

of liver fibrocytes during fibrogenesis has been studied before by Higashiyama et al. (9), who reported that these cells were not important for the development of liver fibrosis. Kupffer cells and infiltrating bone marrow-derived macrophages are a crucial link between chronic inflammation and liver fibrosis (29). However, diverse populations of macrophages are involved in promoting anti-inflammatory effects, as well fibrolysis (29). Macrophage depletion has been shown to compromise fibrolysis during the regression of liver fibrosis (30).

Using bone marrow chimeric mice, the present study has demonstrated the migration of bone marrow-derived cells to the liver, particularly to the fibrous septa, during the development of cirrhosis. A small number of BMC participated in the generation of hepatocytes in chimeric mice submitted to a cirrhosis-inducing protocol. A few $\mathrm{GFP}^{+}$ hepatocytes were also found in chimeric mice and in BMC-transplanted mice chronically infected with
Schistosoma mansoni (31). Previous reports have indicated that the finding of bone marrow-derived hepatocytes may be the result of fusion of BMC with hepatocytes (32). As we did not observe the presence of bone marrow-derived hepatocytes 2 months after cell transplantation, the contribution of these cells to hepatocyte renewal was not found to be relevant to the repair process.

BMC were found mainly in the fibrous septa of BMC-transplanted cirrhotic mice, and promoted regression of fibrosis, suggesting the potential antifibrogenic role of BMC by accelerating the process of fibrosis regression that was observed naturally 2 months after the withdrawal of $\mathrm{CCl}_{4}+\mathrm{EtOH}$. This result was only achieved in the groups of mice treated with repeated injections of $\mathrm{BMC}$ over a 3-week period, and after the withdrawal of $\mathrm{CCl}_{4}+\mathrm{EtOH}$. We were unable to detect any improvement in liver fibrosis when mice were treated with BMC during the cirrhosis induction protocol. In another study, 

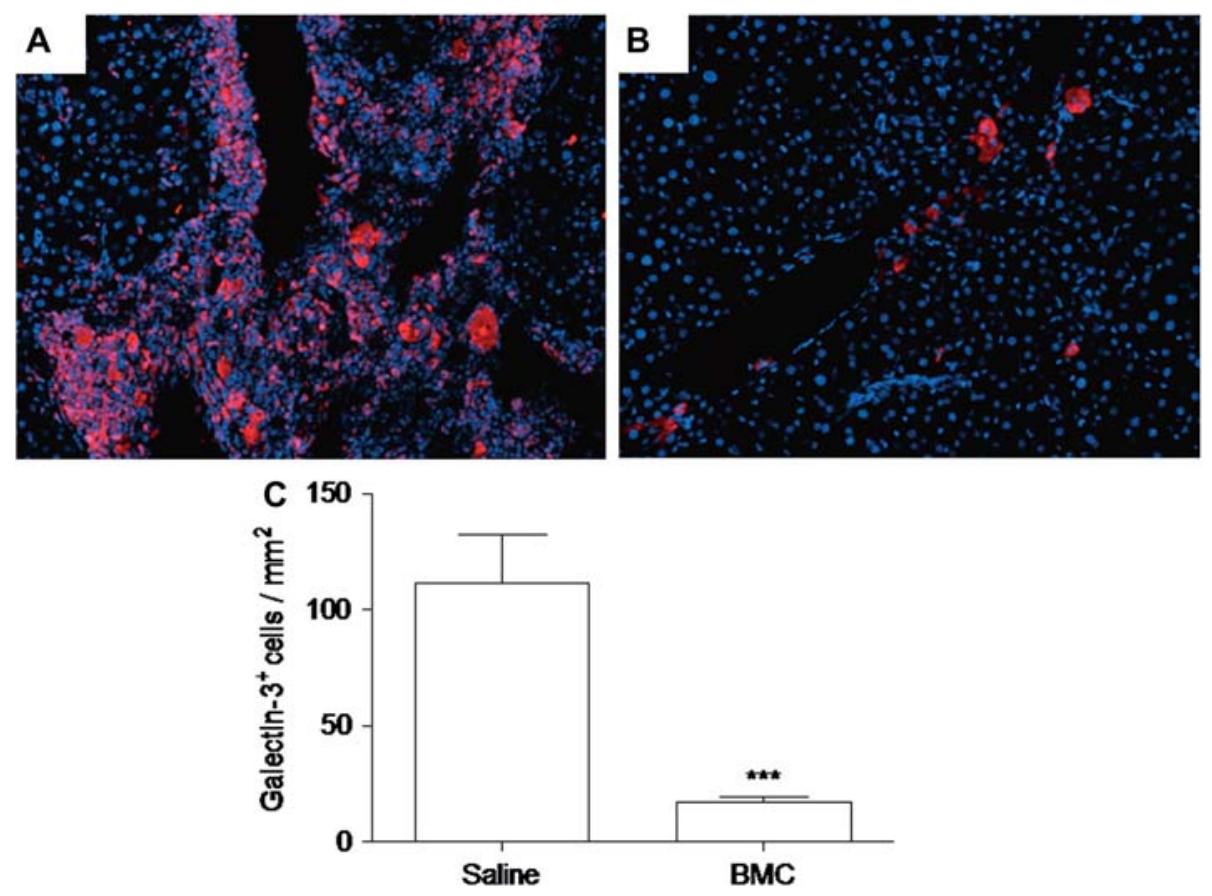

Figure 7. Reduced numbers of galectin- $3^{+}$cells in livers of BMC-treated mice 2 months after therapy. Immunofluorescence for galectin-3 detection (red) in 5-mm frozen liver slices of saline-treated (A) $(400 \times)$ and BMC-treated $(B)(400 \times)$ mice, counterstained with DAPI (blue) for nuclei visualization. Quantification of galectin- $3^{+}$cells in saline-treated and BMC-treated groups (C). Data represent the means \pm SEM of five to eight animals/group. $* * * P<0.0001$

increased fibrosis was found when unfractionated BMC were transplanted into mice that were still being injured by $\mathrm{CCl}_{4}$ (33).

The reduction of fibrosis after BMC transplantation may be because of the modulatory effects exerted by the transplanted cells on non-parenchymatous liver cells. We observed a reduction in the total number of inflammatory cells, including phagocytes. Moreover, in our chronic experimental model, there was a strong relationship between the amount of fibrous tissue and the numbers of galectin $-3^{+}$cells, which were mostly $\mathrm{F} 4 / 80^{+}$macrophages. Macrophages have been shown to be key modulator cells in fibrogenesis, because they produce a number of mediators, including galectin-3 (29). There is evidence that galectin-3 induces a variety of intracellular signaling pathways that lead to the proliferation of hepatic stellate cells (8). This factor is an important activator of fibroblasts (6-8) and plays a pro-fibrotic role by regulating myofibroblast activation during fibrogenesis (7).

TGF- $\beta 1$, a cytokine that promotes fibrosis in many organs, is mainly produced by hepatic stellate cells and stimulates the production of ECM components (34). The present study did not find any significant differences in TGF- $\beta 1 \mathrm{mRNA}$ levels between saline- and BMC-treated groups. Similar results were obtained with protein assessment by enzyme-linked immunosorbent assays (ELISA) in liver fragments (data not shown). This could be explained by the fact that TGF- $\beta 1$, as well as being a known pro-fibrogenic cytokine because of its effect on myofibroblast proliferation and collagen production, it is also a very important anti-inflammatory cytokine (35). In fact, this duality may explain the failure of TGF- $\beta 1$-signaling inhibitors in the treatment of other fibrotic diseases (35). It is possible that a modulation of pro-fibrotic macrophage subsets, rather than a direct modulation of the production of TGF- $\beta 1$, could explain our results. Studies using galectin-3-null mice treated with $\mathrm{CCl}_{4}$ showed that galectin-3 may be required for TGF$\beta$-mediated myofibroblast activation and ECM production (7). Thus the marked reduction in galectin-3 expression after BMC transplantation suggests that the TGF- $\beta$-mediated pathway and, consequently, ECM deposition might be affected by transplanted BMC.

Previous reports have shown the expression of MMP, which are associated with a reduction of liver fibrosis after cell transplantation, by bone marrowderived cells $(19,36)$. It has also been reported previously that liver macrophages can recruit neutrophils during the recovery phase. These cells also express MMP, which promote fibrolysis (37). Although the present study did not find alterations in MMP-9 and TIMP-1 gene expression levels among saline- and BMC-treated cirrhotic mice, it is possible that other MMP, such as MMP-13, may be involved in the 
process of fibrosis regression after cell transplantation $(36,38)$.

In conclusion, the present study has established a mouse model of cirrhosis with morphologic characteristics similar to those found in human cirrhosis, and shown that transplanted BMC migrate to the liver, where they modulate inflammation and fibrosis. The findings of a reduction in fibrous tissue and low galectin-3 expression in animals submitted to cell transplantation reiterate the role this molecule plays in the development of fibrosis, and calls attention to its importance as a target for anti-fibrotic therapies. Additional studies attempting to understand BMC cell populations better and the mechanisms by which BMC transplantation ameliorates hepatic diseases should be conducted to develop successful clinical therapies for liver fibrosis.

Conflict of interest statement: The authors claim they have no conflict of interest in this study.

\section{References}

1. Corrao G, Arico S. Independent and combined action of hepatitis $C$ virus infection and alcohol consumption on the risk of symptomatic liver cirrhosis. Hepatology. 1998;27:914-19.

2. Keeffe EB. Liver transplantation: current status and novel approaches to liver replacement. Gastroenterology. 2001;120: 749-62.

3. Tsui JI, Pletcher MJ, Vittinghoff E, Seal K, Gonzales R. Hepatitis $\mathrm{C}$ and hospital outcomes in patients admitted with alcohol-related problems. J Hepatol. 2006;44:262-6.

4. Dranoff JA, Wells RG. Portal fibroblasts: underappreciated mediators of biliary fibrosis. Hepatology. 2010;51:1438-44.

5. Forbes SJ, Parola M. Liver fibrogenic cells. Best Pract Res Clin Gastroenterol. 2011;25:207-17.

6. Sasaki S, Bao Q, Hughes RC. Galectin-3 modulates rat mesangial cell proliferation and matrix synthesis during experimental glomerulonephritis induced by anti-Thy 1 . 1 antibodies. J Pathol. 1999;187:481-9.

7. Henderson NC, Mackinnon AC, Farnworth SL, Poirier F, Russo FP, Iredale JP, et al. Galectin-3 regulates myofibroblast activation and hepatic fibrosis. Proc Natl Acad Sci USA. 2006;103:5060-5.

8. Maeda N, Kawada N, Seki S, Arakawa T, Ikeda K, et al. Stimulation of proliferation of rat hepatic stellate cells by galectin-1 and galectin-3 through different intracellular signaling pathways. J Biol Chem. 2003;278:18938-44.

9. Higashiyama R, Moro T, Nakao S, Mikami K, et al. Negligible contribution of bone marrow-derived cells to collagen production during hepatic fibrogenesis in mice. Gastroenterology. 2009:137:1459-66.

10. Bataller R, Brenner DA. Liver fibrosis. J Clin Invest. 2005; 115 : 209-18.

11. Neuberger J. Liver transplantation. J Hepatol. 2000;32:198-207.

12. Mimeault M, Hauke R, Batra SK. Stem cells: a revolution in therapeutics - recent advances in stem cell biology and their therapeutic applications in regenerative medicine and cancer therapies. Clin Pharmacol Ther. 2007;82:252-64.

13. Lagasse E, Connors H, Al-Dhalimy M, Reitsma M, Dohse $\mathrm{M}$, et al. Purified hematopoietic stem cells can differentiate into hepatocytes in vivo. Nat Med. 2000;6:1229-34.
14. Oyagi S, Hirose M, Kojima M, Okuyama M, Kawase M, et al. Therapeutic effect of transplanting HGF-treated bone marrow mesenchymal cells into $\mathrm{CCl}_{4}$-injured rats. J Hepatol. 2006;44:742-8.

15. Vassilopoulos G, Wang PR, Russell DW. Transplanted bone marrow regenerates liver by cell fusion. Nature. 2003;422:901-4.

16. Jang YY, Collector MI, Baylin SB, Diehl AM, Sharkis SJ. Hematopoietic stem cells convert into liver cells within days without fusion. Nat Cell Biol. 2004;6:532-9.

17. Caplan AI, Dennis JE. Mesenchymal stem cells as trophic mediators. J Cell Biochem. 2006;98:1076-84.

18. Fang B, Shi M, Liao L, Yang S, Liu Y, et al. Systemic infusion of FLK1(+) mesenchymal stem cells ameliorate carbon tetrachloride-induced liver fibrosis in mice. Transplantation. 2004;78:83-8.

19. Sakaida I, Terai S, Yamamoto N, Aoyama K, Ishikawa T, et al. Transplantation of bone marrow cells reduces $\mathrm{CCl}_{4}$-induced liver fibrosis in mice. Hepatology. 2004;40:1304-11.

20. Zhao DC, Lei JX, Chen R, Yu WH, Zhang XM, et al. Bone marrow-derived mesenchymal stem cells protect against experimental liver fibrosis in rats. World J Gastroenterol. 2005;11:3431-40.

21. Higashiyama R, Inagaki $Y$, Hong $Y Y$, Kushida M, Nakao S, et al. Bone marrow-derived cells express matrix metalloproteinases and contribute to regression of liver fibrosis in mice. Hepatology. 2007;45:213-22.

22. Yannaki E, Athanasiou E, Xagorari A, Constantinou V, Batsis I, et al. G-CSF-primed hematopoietic stem cells or G-CSF per se accelerate recovery and improve survival after liver injury, predominantly by promoting endogenous repair programs. Exp Hematol. 2005;33:108-19.

23. Di Campli C, Piscaglia AC, Pierelli L, Rutella S, Bonanno G, et al. A human umbilical cord stem cell rescue therapy in a murine model of toxic liver injury. Dig Liver Dis. 2004;36:603-13.

24. Tang XP, Yang X, Tan H, Ding YL, Zhang M, et al. Clinical and experimental study on the therapeutic effect of umbilical cord blood transplantation on severe viral hepatitis. World J Gastroenterol. 2003;9:1999-2003.

25. Souza BS, Nogueira RC, De Oliveira SA, De Freitas LA, Lyra LG, et al. Current status of stem cell therapy for liver diseases. Cell Transplant. 2009;18:1261-79.

26. Danguy A, Camby I, Kiss R. Galectins and cancer. Biochim Biophys Acta. 2002;1572:285-93.

27. Lyra AC, Soares MB, da Silva LF, Braga EL, et al. Infusion of autologous bone marrow mononuclear cells through hepatic artery results in a short-term improvement of liver function in patients with chronic liver disease: a pilot randomized controlled study. Eur J Gastroenterol Hepatol. 2010;22:33-42.

28. Kisseleva T, Uchinami H, Feirt N, Quintana-Bustamante O, et al. Bone marrow-derived fibrocytes participate in pathogenesis of liver fibrosis. J Hepatol. 2006;45:429-38.

29. Wynn TA, Barron L. Macrophages: master regulators of inflammation and fibrosis. Semin Liver Dis. 2010;30:245-57.

30. Duffield JS, Forbes SJ, Constandinou CM, Clay S, Partolina $\mathrm{M}$, et al. Selective depletion of macrophages reveals distinct, opposing roles during liver injury and repair. J Clin Invest. 2005;115:56-65.

31. Oliveira SA, Souza BS, Guimaraes-Ferreira CA, Barreto ES, Souza SC, et al. Therapy with bone marrow cells reduces liver alterations in mice chronically infected by Schistosoma mansoni. World J Gastroenterol. 2008;14:5842-50.

32. Wang $\mathrm{X}$, Willenbring $\mathrm{H}$, Akkari $\mathrm{Y}$, Torimaru $\mathrm{Y}$, Foster $\mathrm{M}$, et al. Cell fusion is the principal source of bone-marrowderived hepatocytes. Nature. 2003;422:897-901.

33. Thomas JA, Pope C, Wojtacha D, Robson AJ, Gordon-Walker TT, et al. Macrophage therapy for murine liver fibrosis recruits 
host effector cells improving fibrosis, regeneration and function. Hepatology. 2011;53:2003-15.

34. Gressner AM, Weiskirchen R, Breitkopf K, Dooley S. Roles of TGF-beta in hepatic fibrosis. Front Biosci. 2002;7:793-807.

35. Fattouh R, Jordana M. TGF-beta, eosinophils and IL-13 in allergic airway remodeling: a critical appraisal with therapeutic considerations. Inflamm Allergy Drug Targets. 2008; 7:224-36.

36. Rabani V, Shahsavani M, Gharavi M, Piryaei A, Azhdari Z, et al. Mesenchymal stem cell infusion therapy in a carbon tetrachloride-induced liver fibrosis model affects matrix metalloproteinase expression. Cell Biol Int. 2010;34: $601-5$.

37. Harty MW, Papa EF, Huddleston HM, Young E, Nazareth S, et al. Hepatic macrophages promote the neutrophil-dependent resolution of fibrosis in repairing cholestatic rat livers. Surgery. 2008;143:667-78.

38. Fallowfield JA, Mizuno M, Kendall TJ, Constandinou CM, Benyon RC, et al. Scar- associated macrophages are a major source of hepatic matrix metalloproteinase-13 and facilitate the resolution of murine hepatic fibrosis. J Immunol. 2007; 178:5288-95. 
Copyright of Cytotherapy is the property of Taylor \& Francis Ltd and its content may not be copied or emailed to multiple sites or posted to a listserv without the copyright holder's express written permission. However, users may print, download, or email articles for individual use. 